\title{
Tecnologia móvel e Educação: a utilização do WhatsApp como dispositivo pedagógico no ensino remoto de Eusébio-CE
}

\section{Mobile technology and education: the use of WhatsApp as a pedagogical tool in the remote teaching of Eusébio-CE}

Pedro Henrique Silvestre Nogueira ${ }^{1 *}$, Raphaell Moreira Martins ${ }^{2}$, Cecília Rosa Lacerda ${ }^{3}$, Leandro Nascimento Borges ${ }^{1}$, Symon Tiago Brandão de Souza ${ }^{2}$, Daniel Valério Martins ${ }^{4}$

\begin{abstract}
RESUMO
Esse estudo traz à tona uma experiência educacional, a qual elencou o WhatsApp como o principal dispositivo pedagógico no primeiro ano de pandemia. Objetiva analisar o uso desse aplicativo nos processos de ensino e aprendizagem. Tal estudo, caracterizado como um estudo de caso de cunho qualitativo, foi realizado com nove professoras de uma escola pública localizada no município de Eusébio-CE, por meio de um questionário eletrônico. Como principais resultados constatamos que as professoras passaram a utilizar o WhatsApp de forma intensa; as atividades realizadas por meio dele foram diversificadas, entre as quais se destacam o envio de arquivos, correções de atividades e diálogos com os responsáveis dos alunos. A falta de acesso à internet, dificuldades para avaliar o desempenho acadêmico e problemas relacionados à saúde devido ao uso exacerbado do WhatsApp surgiram como principais fragilidades. Concluímos que pela dinâmica instaurada criou-se uma "pedagogia" do WhatsApp. Contudo, as aulas se aproximaram mais de um entretenimento pedagógico mesmo com todo comprometimento empregado pelas professoras.
\end{abstract}

Palavras-chave: WhatsApp; Pandemia; Processos de ensino e aprendizagem.

\section{ABSTRACT}

This study brings to the fore an educational experience, which cast WhatsApp as the main pedagogical device in the first year of pandemic. It aims to analyze the use of this application in teaching and learning processes. This study, characterized as a qualitative case study, was conducted with nine teachers from a public school located in the municipality of Eusébio-CE, through an electronic questionnaire. As main results we found that the teachers started to use WhatsApp intensely; the activities carried out through it were diversified, among which are the sending of files, corrections of activities and dialogues with the students' guardians. The lack of internet access, difficulties in evaluating academic performance and healthrelated problems due to the exacerbated use of WhatsApp have emerged as major weaknesses. We conclude that the dynamics established created a "pedagogy" of WhatsApp. However, the classes were closer to pedagogical entertainment even with all the commitment employed by the teachers.

Keywords: WhatsApp; Pandemic; Teaching and learning processes.

\footnotetext{
${ }^{1}$ Centro Universitário do Vale do Jaguaribe - UNIJAGUARIBE.

*E-mail: pedro.silvestre@fvj.br

${ }^{2}$ Instituto Federal de Educação, Ciência e Tecnologia do Ceará - IFCE.

${ }^{3}$ Universidade Estadual do Ceará - UECE.

${ }^{4}$ Universidade Federal da Grande Dourados - UFGD.
} 


\section{INTRODUÇÃO}

Historicamente o fazer pedagógico das professoras e dos professores foi e continua sendo marcado por grandes metamorfoses, sejam elas de ordem política, ideológica e/ou metodológica. Até certo tempo bastavam-lhes apenas o conhecimento objetivo e o saber técnico das disciplinas, porém, o surgimento de novas tecnologias e os impactos da ação humana sobre a natureza, como é o caso avassalador da pandemia por COVID-19³ que favoreceu a imposição do ensino remoto emergencial, tem ocasionado outros desafios que ultrapassam a dimensão do ensinar.

Podemos especular entre esses desafios, o domínio de tecnologias educacionais, mesmo que elas já não se apresentem com ar de ineditismo. Na lógica de Lacerda (2018, p. 61) novas experiências de ensino e aprendizagem surgem em decorrência do esgotamento da forma tradicional de ensinar e aprender, "impondo rupturas nos processos complexos que necessitam de compromissos ético-políticos e da reorganização de saberes".

O que se tem como novas estratégias educacionais no período do ensino remoto podem ser consideradas de forma muito bem articuladas como apropriações similares para o ensinar e para o aprender que já coexistam nas instituições de ensino, ou seja, o que temos observado em várias dessas experiências são "capas" que vestem o mesmo universo do ensinar e o do aprender, sem proporcionar inéditos e realmente inovadores acessos ao conhecimento.

Numa tentativa de reorganização mediada por tecnologias, foi visto, entre as principais tecnologias adotadas, a utilização de plataformas de videoconferência, Ambiente Virtual de Aprendizagem (AVA), redes sociais, como também, o acesso de muito conteúdo divulgado na plataforma do YouTube. É razoável destacar especialmente o quanto se aumentou o uso do aplicativo de mensagens WhatsApp para fins educativos.

Fato que chama a atenção para o presente trabalho diz respeito a quantidade de pessoas que utilizam esse aplicativo. Já nos primeiros meses de 2021 foi superado a marca de dois bilhões de usuários ativos em todo planeta, ao passo que no Brasil ele vem sendo o aplicativo mais utilizado entre todos os públicos (SILVA; ALVES, 2018).

\footnotetext{
${ }^{3}$ De acordo com o site oficial do Ministério da Saúde a Covid-19 é uma infecção respiratória aguda causada pelo coronavírus SARS-CoV-2, potencialmente grave, de elevada transmissibilidade e de distribuição global. Disponível em: https://www.gov.br/saude/pt-br/coronavirus/o-que-e-o-coronavirus. Acesso em 20 ago. 2021.
} 
Conforme a Pesquisa Anual do Uso de Tecnologia da Informação, realizada em 2021 pela Faculdade Getúlio Vargas (FGV) a quantidade de dispositivos eletrônicos (celulares, tablets, notebooks) já é maior que o dobro de habitantes. Sem muito esforço é possível perceber que crianças e jovens passaram a ter mais propriedade sobre os aparelhos celulares nos últimos anos.

Apesar de todas as contradições possíveis, a incorporação destes dispositivos tem permitido a comunidade escolar a realização de diversas atividades. Mesmo nas instituições de ensino que adotaram algum AVA, o WhatsApp foi tido como dispositivo auxiliar na organização do trabalho pedagógico. Por outra perspectiva, compreendemos que essa relação dialógica por meio do WhatsApp foi considerada providencial, mas nunca totalmente consensual por parte da classe docente, e em muitos casos, foi o principal fator de desgaste da saúde mental.

Por tudo exposto, acreditamos que com a implementação do ensino remoto, o WhatsApp passou a ser adotado de forma hegemônica nas escolas brasileiras por ser de fácil acesso e possibilitar o compartilhamento de arquivos de mídia com maior rapidez, como ocorreu excepcionalmente em uma escola pública de Eusébio-CE.

A aludida escola foi a única do município a optar por uma proposta alternativa de ensino. Sob a premissa de evitar o aumento da evasão escolar e contemplar a maior quantidade de alunas e alunos que não dispõem de condições necessárias para acompanhar as aulas em ambientes virtuais mais complexos, elegeu o WhatsApp como praticamente o único dispositivo educacional utilizado no primeiro ano da pandemia.

De forma oposta, as demais escolas do município fizeram o uso de plataformas de ensino a distância, sendo a principal delas denominada de "Sala de Aula", idealizada pelo Instituto Tecnológico Educacional Avançado (ITEVA) ${ }^{4}$, que é uma Organização de Sociedade Civil de Interesse Público (OSCIP), sediada no munícipio de Eusébio.

As aulas na referida escola, que, para nossa surpresa, eram ministradas somente por professoras, seguiam a seguinte organização metodológica: todos os dias às 09:00h da manhã as professoras disponibilizavam atividades (exercícios, leituras, pesquisas, dentre outras) nos grupos de WhatsApp de cada turma/série, tendo como principal referência uma apostila confeccionada pela Secretaria de Educação do município e os demais livros didáticos antes já utilizados; a partir daquele horário as professoras ficavam

\footnotetext{
${ }^{4}$ Disponível em: https://www.saladeaula.org.br/
} 
disponíveis para realizar as devidas correções (de forma individual) caso fosse necessário e esclarecer possíveis dúvidas; por volta das 17:00h, período em que geralmente as atividades eram finalizadas pelos alunos, compartilhava-se mais uma vez nos grupos as atividades corrigidas e suas respectivas considerações e correções.

Dado essa contextualização, este estudo teve como objetivo primário analisar o uso do aplicativo WhatsApp nos processos de ensino e aprendizagem no período de pandemia por COVID-19. Dentre os objetivos secundários destacam-se os seguintes: identificar as principais atividades realizadas por meio do WhatsApp; problematizar as fragilidades e possibilidades desse aplicativo nas atividades cotidianas dos professores.

\section{PERCURSO METODOLÓGICO}

\section{Tipo de Estudo e abordagem da pesquisa}

Pela dinâmica que compreende nosso objeto, por exemplo, focalizar um acontecimento contemporâneo, apresentando o que mais possui de singular e ao mesmo tentar responder questões do tipo como e por quê, esta pesquisa pode ser classificada como um estudo de caso intrínseco, o qual possui como principal característica a tentativa de revelar uma experiência inovadora, identificando os elementos que a constituem e que lhe dão sustentação (YIN, 2001).

Por sua vez, a abordagem da pesquisa foi qualitativa, pois não se deteve a mera quantificação dos dados e levou em consideração a dinâmica natural do fenômeno investigado. Martins (2004) salienta que a variedade de material obtido na pesquisa qualitativa demanda da pesquisadora e do pesquisador o desenvolvimento de uma capacidade criadora e intuitiva. A pesquisa qualitativa também produz informações aprofundadas e/ou ilustrativas principalmente quando associada ao estudo de caso, buscando explicações para os porquês dos fenômenos (SILVEIRA; CÓRDOVA, 2009).

\section{Local da Pesquisa}

A pesquisa foi ambientada em uma escola pública do município de Eusébio-CE. O município foi o primeiro do Estado do Ceará a criar o Contraturno e Tempo Integral, modelo em que as/os estudantes permanecem dois expedientes na escola. Atualmente 
possui 37 escolas de ensino fundamental distribuídas ao longo dos seus 23 bairros, contemplando 11.257 alunas e alunos devidamente matriculados (EUSÉBIO, 2021).

\section{Sujeitos da pesquisa}

Participaram da pesquisa nove professoras que atuam nos anos iniciais do ensino fundamental. Para manter preservadas suas identidades e melhor apresentar o município de Eusébio no universo da pesquisa científica, optou-se por evidenciar elementos de sua geografia. Assim, os nomes das professoras foram substituídos por nomes dos principais bairros do referido município.

\section{Instrumento de coleta de dados}

O questionário ${ }^{5}$, composto por questões de múltipla escolha e dissertativas, foi estruturado em três seções que versavam sobre o perfil dos sujeitos da pesquisa, as principais atividades realizadas por meio do WhatsApp e suas implicações nos processos de ensino e aprendizagem. Seu encaminhamento ocorreu por meio da ferramenta google forms. Para Mota (2019) a principal vantagem do google forms em pesquisas acadêmicas é poder acompanhar o andamento de sua pesquisa em tempo real.

\section{Análise dos dados}

Para analisar os dados obtidos optamos pela Análise de Conteúdo proposta por Bardin (2011). A análise de conteúdo é empregada para descrever e interpretar o conteúdo de textos, documentos e demais fontes de dados, permitindo a compreensão dos significados subjacentes. Embora não seja oportuno descrever fielmente todas etapas empregadas em nossa análise, afirmamos que seguimos fielmente o que Bardin (2001) chama de polos cronológicos, são eles: pré-análise (fase de organização propriamente dita); exploração do material (administração sistemática das decisões tomadas anteriormente); tratamento dos resultados, inferência e interpretação (síntese e seleção dos resultados).

\footnotetext{
${ }^{5}$ docs.google.com/forms/d/e/1FAIpQLSdjdmqNGUwnQJrBNYoW914CPAnwacu1Ja8N8YevmQEuwRk Aw/viewform
} 


\section{RESULTADOS E DISCUSSÃO}

\section{Perfil das professoras}

O primeiro bloco de perguntas teve como principal proposta traçar o perfil das nove professoras que participaram da pesquisa. Para tanto, elaborou-se o quadro a seguir explicitando o nome fictício, idade, tempo de docência e maior titulação.

\begin{tabular}{|c|c|c|c|}
\multicolumn{2}{l}{ Quadro 1 - Perfil das professoras } \\
\hline Nome fictício & Idade & Tempo de docência & Maior titulação \\
\hline Jabuti & 56 & 32 & Graduação \\
\hline Tamatanduba & 51 & 30 & Especialização \\
\hline Mangabeira & 31 & 07 & Especialização \\
\hline Guaribas & 33 & 10 & Especialização \\
\hline Lagoinha & 27 & 04 & Especializção \\
\hline Coité & 47 & 30 & Graduação \\
\hline Urucunema & 36 & 02 & Graduação \\
\hline Timbú & 34 & 07 & Especialização \\
\hline Santa Clara & 47 & 30 & Graduação \\
\hline
\end{tabular}

Fonte: Elaborado pelos autores, (2022).

Por meio do quadro, observou-se que, se somarmos todas as idades das professoras e, em seguida, dividirmos pelo total das participantes, que foram nove, teremos como a média dessas idades exatamente 40 anos. Ao estudar o ciclo da vida profissional, ou seja, o percurso de professoras e professores em organizações de ensino, Huberman (1995) apresenta cinco fases da carreira docente, cada uma delas com suas aspirações e singularidades, são elas: entrada na carreira; estabilização; diversificação; distância afetiva ou serenidade; momento de desinvestimento.

Levando em conta que o desenvolvimento de uma carreira compreende um processo dinâmico e não uma série de acontecimentos passíveis de serem previstos, o quadro explicita que a maioria das professoras se aproximam ou possuem entre 30 a 50 anos de idade. Fenômeno este que para o autor poderíamos situá-las na fase conhecida como "meio da carreira", ou seja, a diversificação. São características dessa fase, maior motivação, eficácia, competência, entusiasmo, diversificação de práticas e transformações didático-pedagógicas até então não empreendidas (HUBERMAN, 1995). 
Nota-se que o aspecto da diversificação metodológica que surge nesta etapa da carreira profissional, pode ser analisado como um elemento favorável para as professoras que dormiram forasteiras digitais e tiveram que acordar nativas digitais (MOREIRA; MARTINS; ROCHA, 2020).

\section{Implicações das atividades realizadas pelo WhatsApp}

De posse do perfil das professoras, avançou-se para as questões referentes as atividades desenvolvidas por meio do WhatsApp. Seus aspectos positivos e limitantes foram o principal assunto do segundo bloco de perguntas. As atividades desenvolvidas pelas professoras que mereceram destaque podem ser visualizadas no quadro a seguir:

Quadro 2 - Principais atividades realizadas por meio do WhatsApp

\begin{tabular}{|c|l|}
\hline Acadêmicos & \multicolumn{1}{c|}{ Respostas } \\
\hline Jabuti & "Trabalho com situações problemas, leitura e compreensão de textos". \\
\hline Tamatanduba & "Exercícios, correçôes, conversas com os pais, envio de aulas gravadas". \\
\hline Guaribas & $\begin{array}{l}\text { "Orientações sobre atividades, links com podcast e videos sobre os assuntos } \\
\text { do dia". }\end{array}$ \\
\hline Lagoinha & "Comunicação com alunos, famílias dos alunos e colegas de trabalho". \\
\hline Coité & $\begin{array}{l}\text { "Além das atividades formais da escola, o diálogo com os alunos e suas } \\
\text { famílias". }\end{array}$ \\
\hline Santa Clara & $\begin{array}{l}\text { "Compartilho o conteńdo das aulas no grupo formado por pais, alunos e } \\
\text { núcleo gestor; oriento alunos na execução das atividades; compartilho } \\
\text { informações sobre as atividades extras; realizo periodicamente chamadas de } \\
\text { vídeo". }\end{array}$ \\
\hline
\end{tabular}

Fonte: Elaborado pelos autores, (2022).

Pela intensidade da utilização do WhatsApp já se poderia idealizar que as atividades realizas por meio dele não seriam escassas. $\mathrm{O}$ posicionamento demarcado nesse estudo foi de que a educação proporcionada no ano de 2020 na maioria das escolas brasileiras, esteve mais próxima de um entretenimento pedagógico, já que a grande preocupação se centralizou a diminuir os números da evasão escolar, do que uma educação comprometida com o acesso tematizado do conhecimento historicamente produzido e acumulado pela humanidade. Martins, Nogueira e Souza (2021, p. 379) asseveram que esse conhecimento "[...] exige um aprofundamento progressivo de suas Unidades Temáticas e respectivos objetos de conhecimento, evoluindo em um movimento espiralado ancorado com os grandes temas sociais e a realidade brasileira". 
Concordamos com Martins (2021, p. 97) que tendo em vista tantas adversidades, como a obsessão necrófila de setores reacionários da sociedade civil, que a todo custo almejavam o retorno das aulas presenciais mesmo com o Brasil sendo o epicentro da doença, o que provavelmente aumentaria o número de óbitos, “[...] a classe docente não deixou de trabalhar um único dia sequer desde que a pandemia iniciou".

O que ocorreu, de forma efetiva, foi uma discrepância na carga horária de trabalho, em que muitas vezes, foi impossível computá-la formalmente, aumentando a quantidade de reuniões, exigindo mais horas destinada ao planejamento, orientações aos alunos, atendimentos aos seus pais/responsáveis além de outras atividades que não faziam parte do cotidiano das professoras e dos professores em detrimento da carga horária destinada para as aulas propriamente dita, determinadas nos currículos escolares e previstas em leis.

Inclusive essa relação mais diretiva entre a classe docente e as famílias por meio do WhatsApp foi estabelecida sem a devida mediação social, em inúmeros casos, o que acontecia era uma perseguição e criminalização da classe docente, como se a escolha por esse modelo de ensino fosse de incumbência das professoras e dos professores.

Para ilustrar essa inferência, podemos citar os seguintes cenários, se a professora ou professor utilizava muitas atividades domiciliares, era criticado pelas famílias que argumentavam a dificuldade de acompanhar as atividades das filhas e dos filhos. Se fosse partilhada poucas atividades domiciliares era acusado/a de não está comprometido com o ensino remoto.

Temos até aqui descritas, portanto, as atividades realizadas pelo WhatsApp. Para o fechamento deste bloco, voltou-se o olhar para seus aspectos positivos e negativos. As respostas sobre o primeiro aspecto podem ser observadas no quadro a seguir:

Quadro 3 - Aspectos positivos sobre o uso do WhatsApp

\begin{tabular}{|c|l|}
\hline Acadêmicos & \multicolumn{1}{c|}{ Respostas } \\
\hline Jabuti & $\begin{array}{l}\text { "Nesse periodo de isolamento seria passar informações dos conteúdos e tirar } \\
\text { dúvida sobre as aulas". }\end{array}$ \\
\hline Mangabeira & $\begin{array}{l}\text { "Maior aproximação com a família e diversas possibilidades de aulas com } \\
\text { vídeos, áudio etc.". }\end{array}$ \\
\hline Guaribas & "É uma ferramenta acessivel à todos e de fácil utilização". \\
\hline Lagoinha & "Maior rapidez no repasse das informações da escola". \\
\hline Coité & "A interação entre pais e professores ficou mais próxima". \\
\hline Santa Clara & $\begin{array}{l}\text { "Comunicar com a turma, atendimento individual quando necessário, } \\
\text { registros das atividades que os alunos mandam. Fazer chamadas de vídeo com } \\
\text { a turma". }\end{array}$ \\
\hline
\end{tabular}

Fonte: Elaborado pelos autores, (2022). 
Foi notório, ao menos nos primeiros meses dessa experiência, duas maiores preocupações trazidas pelas professoras, que foram: acolher as famílias e repassar/transmitir o mínimo de conhecimento por meio das possibilidades que o aplicativo oferece. As professoras deixaram claro que isso só foi possível pelo fato de o WhatsApp ser um aplicativo de fácil utilização.

Esse acolhimento se fazia necessário nesta etapa inicial do ensino remoto para a tomada de conhecimento da realidade de cada aluna e de cada aluno, quando estão na escola, fardados e seguindo o rito do ambiente educacional, o nosso olhar inconscientemente torna homogêneo as realidades da classe discente, pois o foco está limitado ao período dentro da escola. No ensino remoto, as realidades eram diversas, e nesse mosaico de possibilidades, poderia ter uma aluna com acesso a internet e um computador para acessar o WhatsApp Web, e outra aluna que ninguém da família sequer tinha celular, e na sua localidade o sinal da internet era precário.

Por sua vez, os aspectos limitantes mencionados pelas professoras giraram em torno de duas grandes categorias, a saber: limites do aplicativo e o agravamento de problemas relacionados à saúde, como mostra o quadro a seguir:

Quadro 4 - Aspectos negativos sobre o uso do WhatsApp

\begin{tabular}{|c|c|}
\hline Acadêmicos & \multicolumn{1}{|c|}{ Respostas } \\
\hline Lagoinha & $\begin{array}{l}\text { "O uso excessivo do aparelho celular, ou aparelhos eletrônicos podem } \\
\text { prejudicar visão, audição, articulaçôes, entre outros". }\end{array}$ \\
\hline Coité & $\begin{array}{l}\text { "A distância é mais complicada de avaliar e saber se os nossos alunos estão } \\
\text { se desenvolvendo bem e tendo um bom desempenho". }\end{array}$ \\
\hline Urucunema & "A quantidade de mensagens recebidas fora de hora". \\
\hline Timbu & $\begin{array}{l}\text { "Quando o uso do mesmo deixa de ser priorizado em consequência de } \\
\text { conversas paralelas como fofocas, brincadeiras, etc.". }\end{array}$ \\
\hline
\end{tabular}

Fonte: Elaborado pelos autores, (2022).

Centrando a análise no contexto da saúde docente em Eusébio, assunto de grande evidência na atual conjuntura de precariedade, (NOGUEIRA, 2021, p. 113), ao se debruçar sobre as práticas curriculares realizadas pelas professoras e pelos professores no período de pandemia, destaca que há um acúmulo de atividades executadas que se estendem, na maioria das vezes, até aos finais de semanas e adverte que: 
atividades burocráticas, como preenchimento de relatórios de alunos, planos de aulas, frequência, exercícios, constantes reuniões, dentre outros que demandam muito tempo do professor e acaba afetando, sobretudo sua saúde mental. Tempo que poderia ser investido em estudos e projetos para melhorias das suas aulas.

Dados da Organização Internacional do Trabalho (OIT) sinalizam a preocupante situação da categoria docente como sendo a segunda classe que mais sofre por doenças ocupacionais a nível mundial. Acompanhado do ritmo de trabalho intenso na pandemia, das diversas formas de precarização, como os contratos de trabalho temporário/intermitentes, do estímulo a competitividade exacerbada, sobretudo quando se aproximam as avaliações de larga escala, esses elementos vorazes se somam a ideia amplamente divulgada no cenário nacional da "reinvenção docente". Para Pereira, Santos e Maneti (2020, p. 29) essas condições atuais de trabalho "podem desencadear patologias relacionadas à saúde mental, como síndrome de Burnout, ansiedade, depressão, suicídio, abuso de álcool e outras drogas, psicossomatização, entre outras”.

Situando a atual gestão educacional pautada na lógica do Accountability (Política de responsabilização) que objetiva alinhar a educação brasileira às demandas e diretrizes do Banco Mundial e do Fundo Monetário Internacional (FMI) para assim promover a suposta "qualidade" de ensino, a ideia da reinvenção docente, que em linhas gerais, podemos a conceber como uma mera "improvisação", transfigura-se em mais uma tentativa ideológica do Estado (governos) e dos proprietários dos estabelecimentos educacionais de se ausentarem das suas responsabilidades e obrigações, enquanto que as professoras e aos professores compete às soluções mais imediatas dos problemas que se apresentam em um cenário cada vez mais complexo.

\section{Limites e possibilidades do WhatsApp nos processos de ensino e aprendizagem}

Até aqui tratamos do uso do WhatsApp sobre os demais aspectos da dinâmica escolar. No terceiro e último bloco do questionário nos deteremos às percepções das professoras, especificamente sobre suas implicações nos processos de ensino e aprendizagem. Ancorado em Libâneo $(2018$, p.8) vale lembrar que esses processos são construídos num ato dialético sob mediação da professora e do professor que visa à “assimilação ativa pelos alunos dos conhecimentos, habilidades e hábitos, atitudes, 
desenvolvendo suas capacidades e habilidades intelectuais”. Para tanto, seus principais limites e fragilidades foram organizados no quadro a seguir.

Quadro 5 - Limites e fragilidades do WhatsApp nos processos de ensino e aprendizagem

\begin{tabular}{|c|l|}
\hline Acadêmicos & \multicolumn{1}{c|}{ Respostas } \\
\hline Jabuti & $\begin{array}{l}\text { "Boa parte dos alunos não tem internet em casa, por isso a aprendizagem } \\
\text { que já era complicada foi muito comprometida". }\end{array}$ \\
\hline Tamatanduba & $\begin{array}{l}\text { "Como qualquer outra via de comunicação, também tem seus limites, suas } \\
\text { fragilidades, pontos positivos e negativos, cabe ao usuário o monitoramento } \\
\text { e acompanhamento para que haja seriedade e respeito". }\end{array}$ \\
\hline Mangabeira & $\begin{array}{l}\text { "Por vezes a interação entre professor e aluno não é a ideal. Pois somente } \\
\text { no presencial temos a real noção se a criança está fazendo as atividades e } \\
\text { sem interferências de outras pessoas". }\end{array}$ \\
\hline Guaribas & "Dificuldade de acesso de alguns. Falta de controle nas devolutivas". \\
\hline Timbu & $\begin{array}{l}\text { "É um recurso limitado porque a interação entre os alunos não acontece, e } \\
\text { a interação individual entre professor e aluno nem sempre é aprofundada } \\
\text { porque é necessário que as informações sejam resumidas". }\end{array}$ \\
\hline
\end{tabular}

Fonte: Elaborado pelos autores, (2022).

Podemos reiterar que os principais entraves se referiram a falta de acesso à internet seguido da impossibilidade de acompanhar de forma efetiva as alunas e os alunos fora do espaço físico da escola, implicando diretamente na interação e autonomia discente, fatores que influenciam diretamente na aprendizagem (LAPLANE, 2000). Todavia, é a sala de aula o lugar privilegiado para trocar ideias, falar, ouvir, ler, escrever e debater. Mas tudo isso tem ficado suspenso com a pandemia.

Retomando um assunto já abordado, porém nessa oportunidade atentando-se ao município de Eusébio, compreendemos que por mais que se tenha aumentado o acesso das/dos estudantes à internet nos últimos anos, fato este que foi também uma preocupação notável das professoras em vários momentos desse estudo, acreditamos que uma razoável parte dos discentes do município não possuem as condições necessárias para lograr êxito no ensino remoto.

Essa constatação encontra respaldo em Marques (2020), que identificou que cerca de $13 \%$ dos estudantes brasileiros, a maioria residindo nas regiões norte e nordeste, afirmam não ter computador e internet de qualidade disponíveis para cumprir as atividades escolares. Se levarmos em consideração as 47,3 milhões de matrículas efetuadas no ano de 2020, o número de estudantes de alguma forma prejudicados representa cerca de 6,14 milhões (BRASIL, 2020). 
Diante dessas circunstâncias, como ter acesso ao ensino mediado pelas tecnologias se lhes faltam a principal condição para isso, ou seja, o acesso à internet? A solução encontrada foi desenvolver apostilas impressas e distribuí-las para os alunos. Porém, mesmo com essa estratégia o aprendizado deles continuou comprometido até pela dificuldade de se chegar à escola, tendo em vista que o serviço de transporte escolar foi cancelado durante a pandemia e os encontros marcados com as professoras na própria escola foram, de certa forma, encontros esporádicos. Isso se deu por diversos motivos.

O principal deles foi a determinação do "Plano Municipal de Contingência para Enfrentamento às Emergências Relacionadas ao Novo Corona Vírus no Município de Eusébio" ", que tem entre seus objetivos viabilizar ações de prevenção e controle do Novo Coronavírus. Para isso orientava a diminuição da circulação das pessoas em espaços públicos coletivos e proibia qualquer atividade presencial em estabelecimentos de serviços não essenciais. Inseridas nesse ínterim estavam as escolas.

Continuando sobre o assunto internet e proporcionando outra perspectiva não menos importante, foi a ideia de que as professoras e os professores possuem uma assinatura de serviços de internet suficiente para o ensino remoto, como se na casa das professoras e dos professores, outras pessoas não precisassem desta conexão em seus afazeres. Sobre esse fato, pouco foi realizado em todo o Brasil, medidas para reparar o investimento que cada professora e cada professor realizou para garantir o ensino remoto desde a utilização de seus próprios aparelhos. Até a conta de energia que ficou mais cara pelo tempo de uso dos aparelhos eletrônicos, entre tantos outros investimentos realizados.

No que diz respeito as possibilidades do WhatsApp nos processos de ensino e aprendizagem, as professoras deixam nítido que o consideram como uma ferramenta para auxiliar no trato pedagógico. No entanto, tendo em vista seu potencial diante do cenário pandêmico, se sobressaem alternativas até então pouco comentadas na educação, entre as quais se destacam sua utilização como ferramenta para melhoria da comunicação entre a comunidade escolar, favorece o aprendizado por meio de outros recursos (textos, áudios, vídeos, pesquisa em sites da internet) ao mesmo tempo em que os pais/responsáveis podem acompanhar em tempo real os conhecimentos acessados pelos alunos. As respostas das professoras que ilustram esse contexto foram descritas no quadro a seguir:

Quadro 6 - Possibilidades do WhatsApp nos processos de ensino e aprendizagem

\footnotetext{
6 Disponível em: http://eusebio.ce.gov.br/wp/wp-content/uploads/2020/03/plano-de-contingencia-novocorona-eusebio-2020-color-pdf.pdf
} 


\begin{tabular}{|c|c|}
\hline Acadêmicos & Respostas \\
\hline Mangabeira & $\begin{array}{l}\text { "Uma ferramenta que veio contribuir de forma enriquecedora e facilitadora } \\
\text { para podermos repassar e dividir o conhecimento junto aos nossos alunos, bem } \\
\text { como a comunidade escolar". }\end{array}$ \\
\hline Guaribas & "É um recurso que facilita a comunicação entre professores, alunos e família. ". \\
\hline Lagoinha & $\begin{array}{l}\text { "Facilidade de repasse se informações, assim como textos, áudio e vídeo } \\
\text { chamada". }\end{array}$ \\
\hline Coité & $\begin{array}{l}\text { "Estar mais conectado com diversas fontes de informação e pesquisa, em um } \\
\text { tempo mais rápido e objetivo". }\end{array}$ \\
\hline Urucunema & $\begin{array}{l}\text { "Utilizando da maneira correta é uma ferramenta para acrescentar ao ensino, } \\
\text { porém jamais substituir o professor". }\end{array}$ \\
\hline Timbú & $\begin{array}{l}\text { "A maior vantagem é que permite o compartilhamento de diferentes recursos } \\
\text { que facilitam o entendimento dos conteúdos: textos informativos, vídeos, cards, } \\
\text { podcast, links para pesquisa, entre outros. Também é essencial a } \\
\text { disponibilidade do professor esclarecendo as possíveis dúvidas. Os alunos que } \\
\text { estiverem dispostos a realmente estudar com responsabilidade, conseguirão ter } \\
\text { um bom aproveitamento". }\end{array}$ \\
\hline
\end{tabular}

Fonte: Elaborado pelos autores, (2022).

A realidade acima descrita, na qual as professoras consideram como pontos positivos, somadas a outras experiências implementadas no período pandêmico pode claramente evoluir para uma discussão mais elaborada sobre os fatores da interação e comunicação, requisitos essenciais para que o processo de ensino e aprendizagem possa acontecer e que foram recorrentes no curso deste estudo. Nesse sentido, sabemos que a qualidade dos processos de ensino e aprendizagem depende de sujeitos em condições sociais e psicológicas ideais que devem ser levadas em consideração, principalmente em tempos tão desafiadores que requerem mais que manter "uma ilusória sensação de que a educação está funcionando a qualquer custo, sem os devidos cuidados éticos, psicológicos, pedagógicos e sociais com professores e estudantes" (MENEZES; FRANCISCO, 2020, p. 1007).

\section{CONSIDERAÇÕES FINAIS}

Pelas mudanças ocasionadas pela pandemia que refletiram na prática pedagógica das professoras, por que não ousar em dizer que se criou, ainda que, de maneira improvisada, uma "pseudopedagogia"? O que poderíamos nomear de pedagogia do WhatsApp - uma vez que, com forte influência do tecnicismo em nosso tempo o sentido de pedagogia tem ganhado novas conotações, passando a ser identificada ao mesmo 
tempo como um conjunto de técnicas e procedimentos favoráveis a uma determinada prática educacional.

Vale resgatar que a escolha pelo WhatsApp como dispositivo aliado da prática pedagógica das professoras partia de um conflituoso dilema que exigia uma tomada consciente de decisões e que requeria principalmente o conhecimento aguçado da realidade social dos alunos. A escolha a ser feita se dava em: aderir as plataformas interativas oferecidas pela Secretaria de Educação do município, mesmo correndo o risco de poucos estudantes permanecerem ao longo do ano letivo ou optar por uma proposta alternativa, na qual fatores como a praticidade, objetividade e universalidade eram seus principais atributos. Ao término desse estudo, não restam dúvidas de que a falta de acesso à internet tornou-se uma das condições limitantes à participação efetiva dos alunos.

Consideramos que o estudo não teve como resultante condenar a opção do aplicativo WhatsApp. Pelo contrário, a partir do momento que a escola adotou esse aplicativo, o nosso interesse foi compreender seus desdobramentos. Dentre os limites e as possibilidades identificadas no tocante o uso do WhatsApp, reconhecemos que para uma situação tão inesperada como o ensino remoto, o aplicativo cumpria algumas necessidades que a escola precisava equacionar naquele momento.

As últimas considerações que podemos determinar se voltam para as professoras que participaram deste estudo e demonstraram um compromisso e um interesse de tentar contornar as dificuldades apresentadas pelo ensino remoto com o máximo de estratégias pedagógicas e iniciativas de garantir o mínimo de acesso ao conhecimento. Por fim, embora não saibamos nesse momento dos possíveis déficits de aprendizagem gerados pela pandemia, acreditamos que os aspectos positivos demarcados pelas professoras precisam ser melhor refletidos e explorados na educação do município de Eusébio.

\section{REFERÊNCIAS}

BARDIN, Laurence. Análise de conteúdo. 11ª ed. São Paulo: Edições 70, 2011.

BRASIL. Instituto Nacional de Estudos e Pesquisas Educacionais Anísio Teixeira. Censo da educação básica 2020: resumo técnico [recurso eletrônico] - Brasília: Inep, 2021. $70 \mathrm{p}$.

EUSÉBIO. Secretaria de Educação. 2021. Disponível em http://eusebio.ce.gov.br/secretarias/secretaria-de-educacao/. Acesso em: 05 mai. 2021.

HUBERMAN, Michael. O ciclo de vida profissional dos professores. In: NÓVOA, António. Vida de professores. Porto Alegre: Porto Editora, 1995. 
LACERDA, Cecília Rosa. Saberes profissionais e aprendizagem da docência no ensino superior. $1^{\text {a }}$ Ed. Fortaleza: EDUECE. 2018.

LAPLANE, Adriana Lia Friszman de. Interação e silêncio na sala de aula. Cadernos Cedes, v. 20, p. 55-69, 2000.

LIBÂNEO, José Carlos. Didática: velhos e novos temas. São Paulo: Cortez Editora, 2018.

MARQUES, Ronualdo. A ressignificação da educação e o processo de ensino e aprendizagem no contexto de pandemia da COVID-19. Boletim de Conjuntura (BOCA), v. 3, n. 7, p. 31-46, 2020.

MARTINS, Heloísa Helena T. Metodologia qualitativa de pesquisa. Educação e pesquisa, v. 30, n. 2, p. 289-300, 2004.

MARTINS, Raphaell Moreira. A interseccionalidade do medo e da ousadia no retorno às aulas presenciais de Educação Física em tempos pandêmicos. Revista Brasileira de Educação Física Escolar, v. Set. 2021, p. 89-105, 2021.

MARTINS, Raphaell Moreira; NOGUEIRA, Pedro Henrique Silvestre; SOUSA, Antonio Carlos de. A percepção das professoras e dos professores sobre a avaliação municipal: o caso do SMAEF. Revista Interdisciplinar em Educação e

Territorialidade-RIET, v. 2, n. 2, p. 368-390, 2021.

MOREIRA, Luiza Silva; MARTINS, Raphaell Moreira; ROCHA, Hugo Paula Almeida da. Dispositivos para educação do corpo e modulação do comportamento nas aulas de educação física: ponto de vista sobre o contexto pandêmico. TEMAS EM

EDUCAÇÃO FÍSICA ESCOLAR, v. 5, p. 2-22, 2020.

MOTA, Janine da Silva. Utilização do google forms na pesquisa acadêmica. Humanidades \& Inovação, v. 6, n. 12, p. 371-373, 2019.

NOGUEIRA, Pedro Henrique Silvestre. Práticas curriculares: um estudo com professores de Educação Física do município de Eusébio-CE. 2021. 145 f. Dissertação (Mestrado Acadêmico em Educação e Ensino) - Universidade Estadual do Ceará Faculdade de Filosofia Dom Aureliano Matos, Limoeiro do Norte, 2021.

PEREIRA, Hortência Pessoa; SANTOS, Fábio Viana; MANENTI, Mariana Aguiar. Saúde mental de docentes em tempos de pandemia: os impactos das atividades remotas. Boletim de Conjuntura (BOCA), v. 3, n. 9, p. 26-32, 2020.

SILVA, Bento Duarte da; ALVES, Elaine Jesus. O aplicativo whatsapp em contextos educativos de letramento digital: Possibilidades e desafios. Revista Observatório, v. 4, n. 5, p. 45-68, 2018.

SILVEIRA, Denise Tolfo; CÓRDOVA, Fernanda Peixoto. A pesquisa científica. In: GERHARDT, Tatiana Engel; SILVEIRA, Denise Tolfo (Org.). Métodos de Pesquisa. Porto Alegre: Editora da UFRGS, 2009. p. 31-42. 
YIN, Robert K. Estudo de caso: planejamento e método. Trad. Daniel Grassi. $2^{\text {a }}$ ed. Porto Alegre: Bookman, 2021.

Recebido em: 03/01/2022

Aprovado em: 25/01/2022

Publicado em: 28/01/2022 